\title{
Mysterious atrial mass mimicking severe mitral stenosis
}

\section{-ilvana Grgić Romić*, DDavorka Lulić, Drinka Matana, - Sandro Brusich, (1)Ante Matana, - Luka Zaputović, 일 Alen Ružić, (DTeodora Zaninović Jurjević}

University of Rijeka, Faculty of Medicine, University Hospital Centre Rijeka, Rijeka, Croatia

\begin{abstract}
KEYWORDS: myxoma, heart neoplasms, mitral valve stenosis.
CITATION: Cardiol Croat. 2019;14(3-4):58-9. | https://doi.org/10.15836/ccar2019.58

*ADDRESS FOR CORRESPONDENCE: Ivana Grgić Romić, Klinički bolnički centar, Krešimirova 42, HR-51000 Rijeka, Croatia. / Phone: +385-91-5773-799 / E-mail: ivana.grgic.ri@gmail.com

ORCID: Ivana Grgić Romić, https://orcid.org/0000-0002-0035-4445 • Davorka Lulić, https://orcid.org/0000-0002-8937-437X Zrinka Matana, https://orcid.org/0000-0002-3086-4980 • Sandro Brusich, https://orcid.org/0000-0001-7394-6698 Ante Matana, https://orcid.org/0000-0003-3630-0374 • Luka Zaputović, https://orcid.org/0000-0001-9415-9618 Alen Ružić, https://orcid.org/0000-0001-5031-2975 • Teodora Zaninović Jurjević, https://orcid.org/0000-0001-8359-3910
\end{abstract}

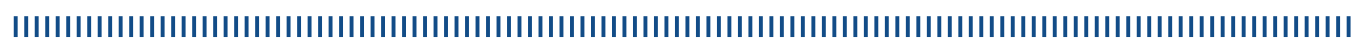

Introduction: The differential diagnosis of an intracardiac mass include benign and malignant primary heart tumors, metastatic tumors and thrombi. Primary tumors of the heart consist mainly of myxomas, with an incidence of less than $0.5 \%$. Clinical manifestations are consequence of embolic phenomena, intracardiac obstruction or constitutional symptoms. In rare instances, myxomas can cause a mass effect, resulting in mitral valve obstruction ${ }^{1}$.

Case report: 68-year-old male with a history of ulcerative colitis complained to his gastroenterologist about having exercise intolerance. Undergoing regular colitis evaluation, CT thorax and abdomen scan was performed incidentally revealing a large intracardiac mass. Echocardiogram ordered by the consulting cardiologist demonstrated a large ellipsoid left atrial cyst ( $50 \times 31 \mathrm{~mm}$ ), occupying nearly the entire left atrium (Figure 1). The mass was protruding across the mitral valve orifice in diastole causing functional stenosis with an elevated mean diastolic gradient of 10,9 mmHg. Mitral

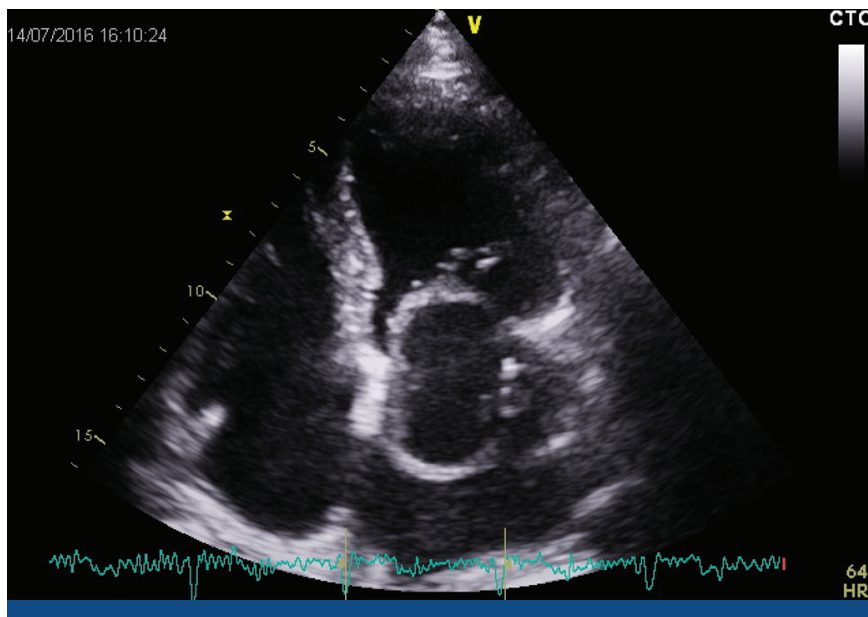

FIGURE 1. Transthoracal echocardiogram apical four chamber view showing a large cyst-like myxoma arising from interatrial septum.

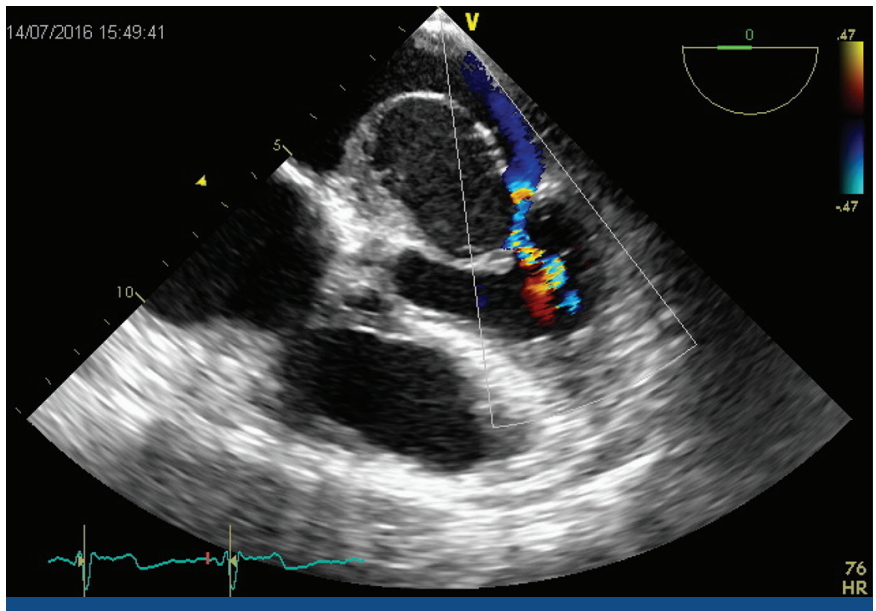

FIGURE 2. Transesophageal echocardiogram four chamber view - color Doppler showing the myxoma in the left atrium causing near complete mitral valve obstruction.
RECEIVED:

February 28, 2019

ACCEPTED:

March 24, 2019

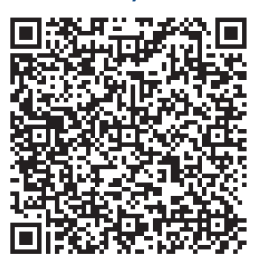

$\square$ Cardiologia Croatica 2019;14(3-4):58. valve area calculated by pressure half-time was $1.0 \mathrm{~cm}^{2}$. Doppler showed moderate tricuspid regurgitation with a systolic pulmonary artery pressure of $50 \mathrm{mmHg}$. The systolic function was preserved with an estimated left ventricular ejection fraction of 58\%. Transesophageal echocardiography described a cavitating lesion (measuring 15,1 $\mathrm{cm}^{2}$ attached to interatrial septum with $24 \mathrm{~mm}$ base), having characteristics consistent with a hemorrhagic cyst (Figure 2). Preoperative coronary angiography displayed coronary artery disease and a rare condition of dual coronary artery supply with left circumflex artery (LCx) providing two (Figure 3) and right coronary artery (RCA) one tumor branch (Figure 4) producing a characteric "tumor blush". CT showed large intracardiac mass (Figure $\mathbf{5}$ and Figure 6). Patient underwent cardiothoracic surgery with successful excision of the tumor $(4,5 \times 3 \times 2 \mathrm{~cm})$, the pathohistology 


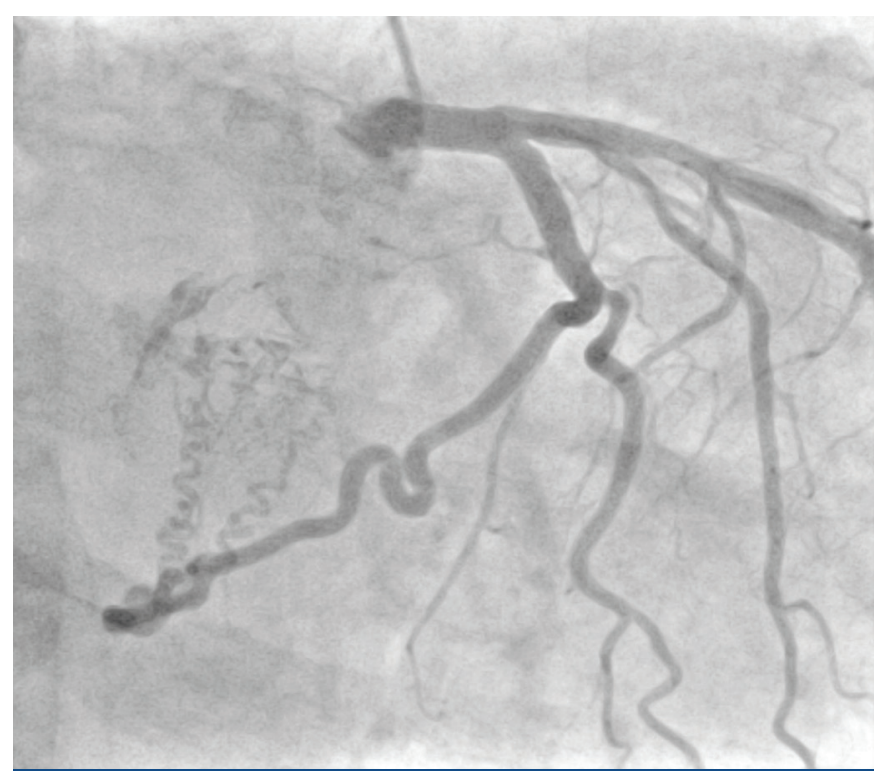

FIGURE 3. Coronary angiography showing the left circumflex artery supplying the intracardiac tumor with two anomalous branches.
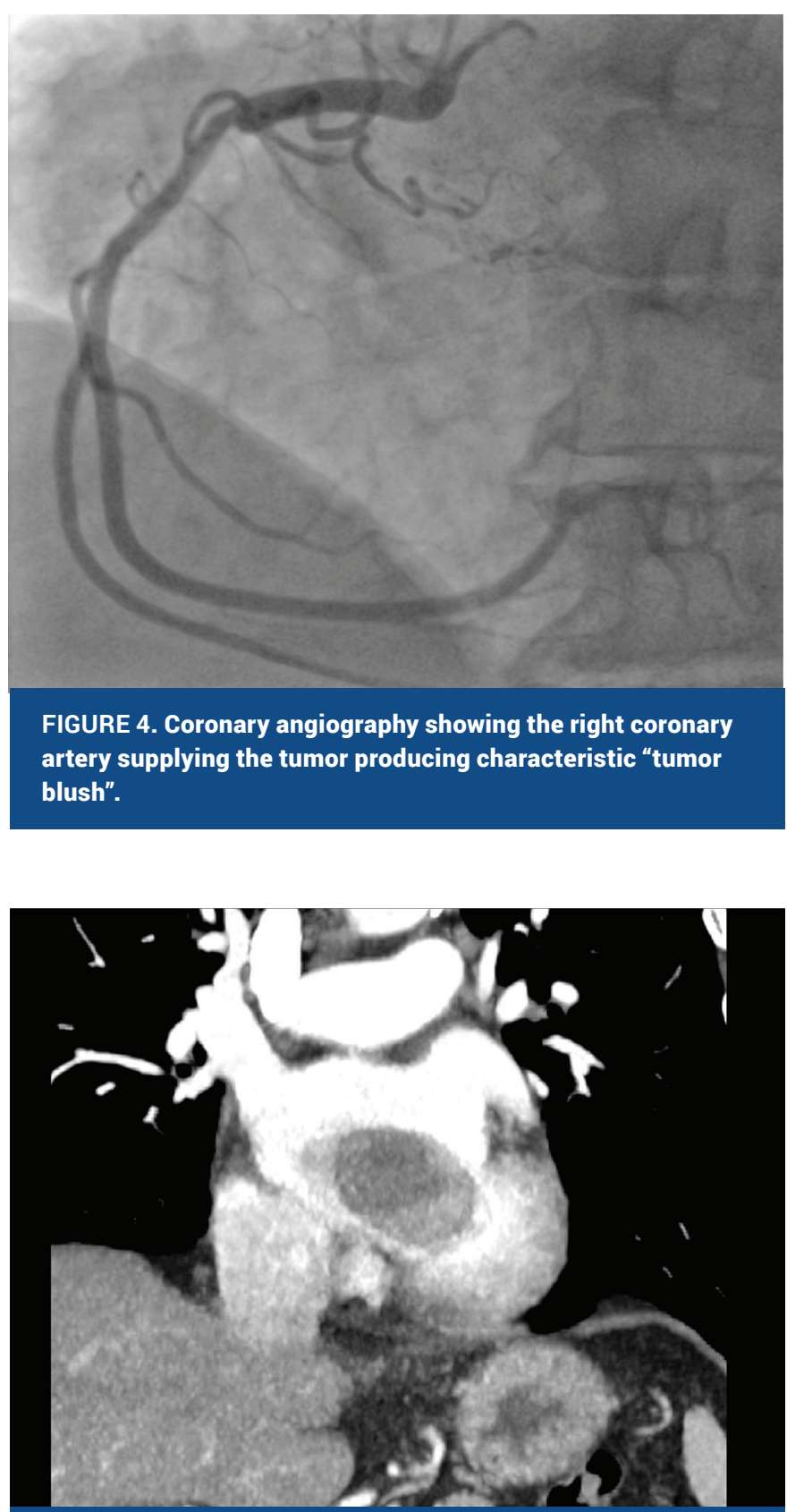

FIGURE 6. CT cardiac image showing large intracardiac mass.

FIGURE 5. Contrast enhanced axial CT scan showing minimal enhancenemt of the mass.

confirmed myxoma. Postoperative course was uneventful, exercise intolerance symptoms improved, and echocardiographic follow up showed no intracardiac mass.

Conclusion: We described a rare case of cystic-appearance cardiac myxoma with dual coronary supply mimicking mitral valve stenosis. There are not many patients reported with left atrial myxoma being vascularized from both RCA and LCx as seen in our case ${ }^{2}$ Although more than half of atrial myxomas show obstructive symptoms, severe mitral valve obstruction is rare ${ }^{1}$. Early echocardiographic examination of patients presenting with exertional dyspnea is advised, as myxomas have an excellent prognosis following surgical excision, preventing complications and improving quality of life.

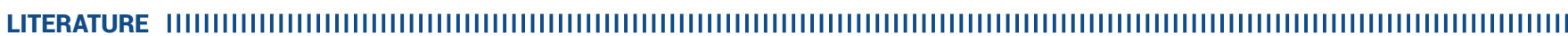

1. Pinede L, Duhaut P, Loire R. Clinical presentation of left atrial cardiac myxoma. A series of 112 consecutive cases. Medicine (Baltimore). 2001 May;80(3):159-72. PubMed: https://www.ncbi.nlm.nih.gov/pubmed/11388092

2. Omar HR. The value of coronary angiography in the work-up of atrial myxomas. Herz. 2015 May;40(3):442-6. https://doi.org/10.1007/s00059-013-3930-z 